\title{
Addressing customer myopia: Strategic interactive marketing planning in a volatile business environment
}

Received (in revised form): 23rd October, 2001

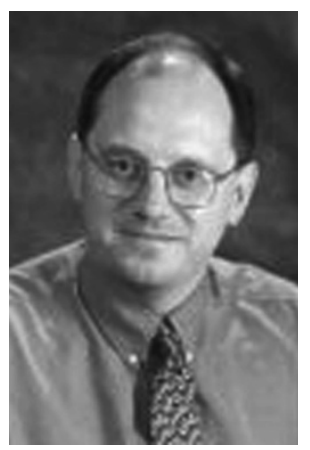

\section{Terry Kendrick}

is a strategic marketing planning and information consultant who since 1984 has worked on consultancy projects for over 50 organisations in 17 countries. Projects have ranged from facilitating marketing plans and developing key account management processes to the analysis of customer attractiveness and profitability issues in specific companies.

\section{Keith Fletcher}

is Professor of Management at the University of East Anglia and was founding Dean of the School of Management. He has lectured extensively overseas and is Chair of the East of England network for Interactive Marketing. He gained his doctorate in consumer decision making and his research interests include consumer behaviour, strategy formulation and implementation, and CRM.

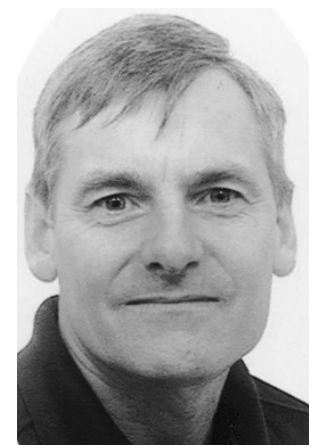

Abstract This paper introduces and examines the concept of customer myopia, which is the over-reliance on the existing customer base rather than studying the whole market of potential and future customers. Eight assumptions are studied which illustrate customer myopia and the argument for a strategic perspective is put. How to implement strategic interactive marketing planning (SIMP) is explained in nine stages, within two phases.

\section{INTRODUCTION}

Traditional marketing planning and acquisition marketing has been criticised as being product or sales focused and customer retention and relationships have been seen as the drivers for profitable growth. Now is the time to question whether excessive attention to the existing customer base is the optimum way to ensure long-term profitable growth.

This paper looks at the synthesis of customer relationship management (CRM) and traditional marketing planning approaches with interactive marketing as the catalyst to provide a meaningful business future for long-term players. Interactive marketing is the combination of traditional marketing principles with CRM methods and technology to build relationships and acquire new customers.

In companies where heavily sales-led approaches had resulted in mindless customer acquisition, regardless of inherent profitability, CRM has promised business growth. In these companies existing customers, with lower cost structures, had been neglected with the consequent loss of potential profit. The promise of CRM was that it improved lifetime value by adding relationship and service marketing concepts to database marketing. This allowed the building of successful retention approaches. Various examples were given which showed the 
major impact this could have on longer-term profitability. ${ }^{1}$

It is, however, clear that the evangelical fervour of some CRM proponents has not always delivered the expected returns and the Alexander Group suggest that $60-80$ per cent of CRM projects are deemed to be unsuccessful. $^{2}$ A report by Gartner suggests that more than half of all companies implementing CRM initiatives today will view those plans as failures by 2006. Gartner attributes these failures to a range of problems, including poor channel integration and the absence of a true process redesign. ${ }^{3}$ It is possible, however, that another contributory and, indeed, unifying factor could be the drift away from sustained clear thinking strategic marketing planning - a process which requires a clear linking of strategic gaps, market analysis and integrated applications. ${ }^{4,5}$

This paper highlights a number of the key questionable assumptions that underpin some CRM thinking and planning. It resolves these issues by introducing the concept of strategic interactive marketing planning, a synthesis of CRM and traditional marketing planning.

The authors' belief is that CRM is an excellent core strategy for those few companies that already have the best customers in their industry (and where these customers are likely to be the best customers in the industry in the future), and where both partners, company and customer, are likely to want to enter into a relationship.

Where a company has only a small portion of 'best industry customers' in its portfolio a mixture of alternative approaches will be needed. Similarly, where buyers are switchers and do not want to enter relationships then reputation and brand building may be required through mass marketing. CRM loyalty approaches will need to be balanced with more traditional customer acquisition approaches to take into account the volatile customer base and changing business environment. Unfortunately, this does not seem to be happening and integrated marketing strategy is not being implemented.

Strategic interactive marketing planning, bringing together the best of these approaches, looks likely to gain increasing importance in the next few years as companies recognise that to ensure they maximise profitability a new synthesis of business approaches and models is required.

\section{CUSTOMER MYOPIA}

In certain circumstances market conditions could lead a business to customer myopia. Customer myopia is defined as a short-sighted over-reliance on the existing customer base rather than studying the whole market of potential and future customers. Companies must always remain alert to where their future profits will come from, and not simply assume today's profitable customer will provide profitable business in three to five years' time. Levitt introduced the idea of marketing myopia ${ }^{6}$ to explain the short-sighted focus on the product, rather than the benefits the product gave. $\mathrm{He}$ warned that focusing on present products rather than benefits to the customer meant that future innovative products from competitors were ignored, as they did not fit the mindset of the business.

Many of the dangers Levitt highlighted have now been recognised by companies, and CRM has encouraged the move away from the product focus to the customer. CRM also has some dangers however. By focusing too narrowly on the nature of existing customers, the opportunities from future customers may well be ignored. 
Customer myopia will manifest itself in an over focus on retention and relationship marketing. To achieve this the concentration is on data warehousing, collecting data from more and more contact points in the hope of differentiating actual customers. Patterns in the existing customer base will be studied, and product and service offerings customised, without questioning whether the existing customer base is the right one for the future.

Sources of future profits in a future business environment may be significantly different to the existing market conditions. By analysing existing customers too closely aspects of the changing environment, such as new markets, may well be missed. Peppers and Rogers give the example of IBM, who by staying too close to its mainframe customers missed the early wave of PC growth by not conceiving how the new market would revolutionise its own business. Other leading companies may well be falling into a similar trap.

Despite this, an example of this customer myopia is actually given by Peppers and Rogers when they champion a dry cleaning company. The dry cleaning company is quoted as saying:

'Instead of trying to get as many dry cleaning customers in town as possible, we will try to get more business from each of the customers we already have. We'll make sure to get all the dry cleaning repairs and alterations, speciality cleaning and so forth for each of them forever, as well as win direct referral business.'

Now, while it is clearly a good idea for a business to sell more of what it does already to those customers it already knows well, the fervour of the quoted dry cleaning company is based on assumptions which are, to say the very least, questionable. By looking at these assumptions customer myopia can be illustrated.

Assumption 1. The remaining share of customer spend is significant and worth having. In the example above what is the 'dry-cleaning-bill-not-already-achieved'? If a business already has the easy 80 per cent of a customer's total potential spend, will investing in winning the final notional 20 per cent really provide sound growth? When contrasted with the easy 80 per cent of a new customer's potential spend which is the better investment? Of an existing customer's five dry cleaning purchases per year the initial four may be profitably won but the final one may, for a number of reasons, be less easy to achieve.

Assumption 2. The lifetime values of customers are worth having and investing in. In addition to the potentially modest level of customer value to be won, businesses need to take account of the real lifetime of their customers. If people move home on average every seven years then it is unlikely, for the dry cleaning example, that, on moving, the same outlet will be used, or even necessarily the same chain. Location and convenience are more likely choice criteria resulting in short life times for most customers. In many markets with changing and temporary needs recognising the potential new customer is more important than stopping the exit of the old.

Assumption 3. Customers care about and are involved with products. Where products are distress or low-involvement purchases then loyalty and relationship issues are not likely to apply in choosing an outlet. In the case of dry cleaning how important a decision is it? While many companies believe their products or services should be seen as important, high-involvement products, often this is 
not the case. It may, as the mantra goes, cost more to win a new customer than to keep an existing customer but churn may be a natural market dynamic not easily influenced by CRM tools and techniques. Some customers can be developed and some cannot.

Assumption 4. Getting customer relationship management right leads to loyalty which should ensure that competitors will not get another business's customers. This may be a necessary (and even that is questionable) but it is certainly not a sufficient condition to ensure continuing sales. The word 'loyalty', when based upon behaviour, becomes little more than propensity to not change and two or three purchases allocate a customer to the 'loyal' bracket. ${ }^{8,9}$ Under such rules, however, customers are loyal to Tesco, Sainsbury, Iceland and the local corner shop. Such a definition of loyalty becomes meaningless - logicians might call it the 'death of a thousand loyalties'. Customer loyalty is nothing more than the fact that they have passed that way and wanted something and have done this on more than one occasion. Loyalty is something supporters have to a football team. It does not matter how often the team loses the supporters will return and are loyal. How many will return to their favourite dry cleaning shop if the service is consistently poor and the product does not deliver?

In addition, customers are not always persuaded by reason and the best offer does not always win. Satisfied customers defect, given the right incentive, or simply want a change of supplier. For the dry cleaner in the example to talk about getting business 'forever' is patently unrealistic.

Assumption 5. Present customers are the best customers. A recent market entrant may 'buy' itself a significant customer base, high on numbers, low on profitability. Is it right for such a company to develop its existing customer base, except on the grounds that those are the only customers they have? It is clearly theoretically possible for a company to discover that its customer base is simply those customers that competitors do not want. The authors' consulting experience suggests that this is not just theoretical but can have frightening resonance when companies are confronted with this possibility.

Assumption 6. With better information in its customer information file a business can understand its customers better. CRM systems are always based upon a very limited amount of information about the marketplace and customers. A company will never have perfect information about its customers allowing a truly one-to-one relationship. Customers lie, change over time, and will not be pigeonholed into segments. Companies analyse very few of their customer data, some analysts suggesting that most companies actually analyse less than half of the data they collect.

Assumption 7. Given information on customers, knowing what to do with it will be easy. Even when attempts are made to analyse data, conclusions do not come easily. Should it be concluded that 80 per cent of customers would choose the business next time just because their tear-off slip says they will? Disciples of CRM and one-to-one marketing can sometimes exhibit excessive faith in statistical techniques. They show symptoms of customer myopia, deluding themselves into believing that they have a greater influence over customers' buying patterns than in reality they have. Modelling such behaviour is too time consuming and its predictive value is questionable.

Assumption 8. The future will be similar to today. Focusing on existing customers assumes that if a particular type of customer is profitable today then they 
will continue to be so. Is this true? Large customers may be profitable today but the future profitable customers may not be the same as at present. CRM does not always highlight what is possible within a marketplace even when it can highlight what is possible within the existing customer base. Some might argue that there is no need to look very far beyond the existing customer base if the returns from that are sufficient to satisfy shareholders. Caution is, however, urged here. To exist happily on a fully developed existing customer base may allow competitors to exploit other areas of the market with the consequent experience allowing them to become significant competitors in the business's core customer market.

Undoubtedly, CRM approaches are an important part of good business practice but, as these assumptions and tendencies above show, there is great potential for customer myopia. There are clearly businesses where most effort should be spent on existing customers and in these markets many benefits can be achieved. A balance to retention over acquisition should be continued where:

- the market is mature with little growth

- the business has a set of some of the most profitable customers in the industry

- competitors cannot easily copy and better the business's best offers

- customers have high involvement and desire added value

- the product/service features need regular maintenance, there is a high purchase frequency or there are high switching costs.

If, however, the business has some of the worst customers in the industry as its portfolio, or they will become so in the future, then this does not make sense.
Customers are not distributed equally by profitability throughout the industry in some mystical way. Some competitors have better customer portfolios than others do. If a business has a poor portfolio then it should get new customers. A customer retention strategy for a company with an unprofitable portfolio, which has no realistic way of being turned around in the next three years, is clearly not operating on a sound business model.

\section{THE SOLUTION: STRATEGIC PERSPECTIVE ON CRM}

Effective CRM processes ensure that elements of relationship and service marketing such as technology, tools, processes and people are front of mind throughout the marketing planning process. These elements, however, need direction to ensure that the outcomes of the improved information flows, such as improved service and greater efficiency, are translated into meaningful strategic thrusts. ${ }^{10-12}$ This direction can be lost if CRM develops management processes that are separate from strategic marketing planning.

An essential difference exists, however, in CRM planning between two types of company in relationship to the barriers likely to inhibit successful adoption and implementation of CRM. ${ }^{13,14}$ A key market for many IT consultants is those companies which are considering the move to CRM, but do not have the customer information or technology which would allow them to take the first step. For these businesses, before they can accept adoption of CRM processes, a business case will need to be created that justifies the major technological investment required to build the customer information file and manage the customer interactions. For these companies the degree of organisational 
change required can be substantial and a danger is that the software choice and installation distorts the purpose of the exercise. The difficulty for many of these companies is that having implemented the system they often do not know what to do with it. Some useful guidelines have been produced which attempt to overcome these problems. ${ }^{15-17}$

Other businesses may have taken the first steps to implement a process, and may already have identified customers, but have not a sophisticated CRM system, or have not found CRM applications successful. A subset of this group would be business-to-business companies and small to medium size enterprises (SMEs) ${ }^{18}$ who because of their smaller customer base may already be practising key account management for some customers but are having difficulty integrating the two differing frameworks. The important factors which need to be considered for the adopter companies are fundamentally different from those needed in the later implementation stages $^{19}$ and this needs to be considered in the strategic planning process.

Sophisticated CRM adoption, particularly for the first group, has the clear potential to deflect attention away from the changing business environment. This may lead to the appropriate customer base being ignored in three to five years' time. To make CRM applications work the CRM process needs to be driven from the outside in, understanding customers' needs but ensuring strategic processes and CRM application functionality are aligned. ${ }^{20}$ The CRM processes in themselves will not drive growth objectives, and these need to be implemented into an overall framework that manages all aspects of the change process.

The context for any traditional strategic marketing planning process is the identification of corporate objectives and ambition (both in terms of general mission, vision, values and financial objectives and shareholder requirements). Once identified and agreed this is typically followed by a situational analysis or marketing audit, leading to a summary in a SWOT analysis. Out of these analytical stages the marketing objectives and strategy are determined, based on the factors previously noted as relevant to the company. When proposed strategies are agreed to be strong enough to deliver the level of corporate ambition and corporate financial objectives these are then implemented through a detailed action plan.

During implementation the whole process is monitored to ensure that the actions are implemented and that the chosen strategies are indeed delivering the marketing and financial objectives and ambition set out by the company in the early stages of the planning process.

Utilising this planning approach, as outlined in McDonald's well-known ten-stage process, ${ }^{21}$ may, despite its potential for including many interactive marketing elements, lead to a process-driven, fill-in-the-box marketing planning process. Used in an unsophisticated way both marketing planning and CRM approaches have the potential to deflect attention away from good marketing management in companies.

A close CRM-driven analysis of the current customer base is crucial to effective business planning but for sound business planning this should also be in the context of a wider marketing planning process which integrates all elements.

In reality, both marketing planning and CRM approaches are complementary, even if they are often seen as separate initiatives within companies. Frequently, company organisation structures do not reflect the degree of alignment required 
for effective business growth and development. $^{22,23}$ In the authors' consulting and related activities it is not unusual to see CRM and strategic marketing planning projects led by different teams and an internal rivalry can develop which is not to the benefit of the business. In one major financial services company, for instance, traditional marketing activity is organised around product lines and CRM activities are organised around customer groupings administered in a separate building.

Given this need to align CRM and marketing planning approaches the authors advocate strategic interactive marketing planning (SIMP) as a response.

The following outline process offers an approach to undertaking CRM within a wider business and marketing planning context. It ensures that a business or marketing planning process is always considering the importance of customer retention and management, while at the same time protecting CRM practitioners from customer myopia.

\section{HOW TO DEVELOP THE STRATEGIC INTERACTIVE MARKETING PLANNING (SIMP) STAGES}

SIMP is best thought of as nine stages, within two phases. Phase One is essentially based around the question 'Where's the best business?' The stages are based on agreeing corporate ambition and objectives, analysing the existing customer base, analysing the potential customer base, concluding with an assessment of the business' readiness for effective marketing planning and CRM.

Phase Two is essentially based around the subsequent question 'How will we win it?' The process has stages based on an implementation gap analysis, planning and CRM objectives, developing an interactive marketing strategy, formulating an interactive action plan and concluding with a statement of planning and CRM milestones and implementing monitoring procedures.

In more detail these phases and stages involve addressing the following key questions.

\section{Phase 1: 'Where's the best business?'}

\section{Stage 1: Agreeing business ambition and corporate objectives}

Without a clear idea of level of ambition and corporate objectives there is no context for developing marketing planning and CRM approaches. Strong ambition will often require a balance towards innovative rather than continuous improvement approaches while modest ambition will suggest priority be given to continuous improvement rather than innovation. The level of ambition will help make the decision in the later stages of the process as to the relative balance of customer retention/acquisition and one-to-one/mass marketing.

This stage is about being reasonable and challenging and sets the context for the amount and type of business that the strategic interactive marketing plan should chase and, through implementation, win. The future is unlikely to be similar to today and there should be a feedback loop to enable later understandings to influence this ambition. Discussion in this stage will focus on questions such as:

- what is the business idea (vision/mission/values)

- how will the business know if it is succeeding

- what will be the financial and other measures (such as market share) which can be monitored to judge progress? 


\section{Stage 2: Analysing the existing customer base}

This analysis should assess the contribution of the current customer base to the longer-term future in the three to five year ambitions of the business. The analysis of existing customers will allow companies to determine the characteristics of their 'best' customers, compared to their 'worst', ${ }^{24}$ and to determine the ability to change the buying patterns of existing customers. This may well involve an analysis of the customer involvement to see which, if any, of the business's customers care about and are involved with its products. A critical element of this stage is to consider the likelihood that these 'best' customers might be seduced by competitors, and the critical elements that make them have a commitment and loyalty to the business. The assumption that if a business gets customer relationship management right then competitors will not get its customers' business should be tested. Key questions for this stage are:

— is the remaining share of customer spend significant and worth having

- are the lifetime values of customers worth having and investing in

- where are the business's most profitable customers both now and in the longer-term planning horizon (customer profitability analysis)

- can customer differences be analysed and capitalised on (segmentation)

- how much might the business expect them to contribute towards its longer-term ambitions (customer profitability analysis)

- where might their custom be in the future and what does that mean for the target business's chances of retaining their custom (key account management and account management)
- how likely is it that these customers will be with the business in three to five years' time and what will they be worth to it (lifetime values)

- how confident is the business that it can deflect competitive threats (competitive analysis)

- what will it take for the business to retain and develop its customers' business with it over the planning period (customer experience management)

- which customers are likely to respond best to a relationship approach, which to a transactional approach?

\section{Stage 3: Analysing the potential customer base}

The analysis of present customers and competitive threats will allow a much clearer understanding of the nature of new markets which might be available to the business by identifying unfulfilled opportunities. Are present customers the best customers, will the new customers look like the old, and have the same needs, or will a new set of sales criteria be needed? This stage develops a high level plan of market opportunities for replacement business or growth. Key questions for this stage are:

— in addition to existing customers what customers are out there to be won

- what levels of investment are required to win them

— will investment levels allow one-to-one marketing or will a segmentation approach supported by mass marketing be the most appropriate way forward

- who 'owns' these customers at present, and how will they react when the business makes a play for them? 


\section{Stage 4: Strategic gap analysis}

This stage assesses the position of the business to meet opportunities identified in previous stages. Key strategic questions include:

- does the business understand the market environment both now and any changes that might occur during the coming years

- is the business confident that it can survive volatile market conditions given the range of potential scenarios that might occur

- given satisfactory answers to these questions what are the business's strengths, competencies and weaknesses

- has the business sufficient customer information to develop sound strategies

- does the business provide a single face to the customer

- are the business's processes product or customer driven

- has the business a robust understanding of competitors and their place in its market both now and in the future?

\section{Phase 2: How will the business win it?}

\section{Stage 5: Implementation gap analysis}

This stage investigates the barriers or constraints to implementing existing or new strategies. What is stopping a business getting there now? Established CRM players may well have many of the people, processes, tools and customer information already in place. Other companies may well have to focus on improving in some areas before marketing applications can be successful. As argued earlier, a stages model suggests that differing problems will be faced depending on the present stage of development. ${ }^{25}$ This stage ensures that company structures reflect the degree of alignment required for effective business growth and development. Various CRM benchmarking tools exist which can help companies understand their capabilities in these areas. These tools include CMAT by QCi, the AMS iCVM Gap scorecard and Hewson's Benchmarking Group. A summary of the type of issues to be discussed is:

- technology issues: present state of customer information system

- information issues: customer data and modelling capabilities

- process issues: degree of customer service focus in key touchpoints

- communication issues: customer contact channels

- measurement issues: performance measures

- people and organisation issues: management and employee flexibility.

\section{Stage 6: Planning and CRM objectives}

As argued above both marketing planning and CRM approaches are complementary, even if they are often seen as separate initiatives within companies. This stage ensures they are integrated successfully. The assumption of CRM is that given information about customers knowing what to do with it will be easy. This is seldom the case and 'analysis paralysis' seems to have hit some firms with large customer databases. In stages 3 and 4 judgments will have been made, in principle, on the relative importance of types of business (existing or new customers) which are expected to deliver the corporate objectives. Given these corporate objectives:

- how much of this requirement will be met by mass, segmented or one-to-one approaches 
- where is there scope for relationship development, and which segments are simply transactional

— will growth be from existing customers either by increasing retention, upselling or cross-selling

- how much of the business's profit objectives will be met by new customers or segments

- over what time period is the business intending to grow these markets, or upgrade these customers

- how will the business measure success in its marketing strategies

- are the business's objectives complementary or isolated

- what changes is the business investing in based on the findings of stage 5 ?

\section{Stage 7: Interactive marketing strategy}

This stage determines and designs the interactive marketing strategy to meet the objectives from the previous stage. It makes decisions on the best way to deliver the overall planning and CRM objectives. Key questions in this stage are:

- how will one-to-one CRM and mass marketing approaches be combined to deliver the objectives

- how will customers be identified and targeted

- how will customer upgrading be achieved

- what marketing communications will need to be produced and implemented

- what contact strategies are required

- is the current product range appropriate or will investment in new products and services be required

- what customisation is required

- what principles will support pricing decisions
- how will distribution channels, including the Internet, best support business development?

\section{Stage 8: The interactive action plan}

A well-developed strategy to integrate traditional marketing planning mass marketing and CRM approaches will require a robust action implementation plan. Key questions this stage will answer include:

- what needs to be done to deliver the strategies

- when should these things be done

- who should be responsible for ensuring they are done

- are the actions consistent with the strategies

- is there enough action to implement the strategies far enough during the planning period

- what feedback mechanisms are there to manage the process

- has enough resource been allocated to implement the strategies in the intended way?

\section{Stage 9: Milestones and monitoring}

The move to implement CRM may need a major process of change management as processes and information flows are modified. Alternatively, for some businesses, key account management principles can be extended to include the wider marketplace. A process of mentoring is necessary during the implementation stage to ensure the integration process is monitored and essential objectives achieved. This stage may well last the entire life of the business strategy to ensure no bottlenecks or barriers divert the initial business strategy.

The key milestones are identified to check that strategy deployment is effective and implementation monitored. 


\section{CONCLUSIONS}

There are circumstances where relationship marketing and retention alone will not deliver a long-term stable business. There is thus an urgent need to place CRM in the context of the wider world to avoid customer myopia. CRM is a valuable business initiative, but only within the context of a wider marketing planning strategy. Companies need to know:

- given the current volatility, they can survive given a wide range of alternative scenarios

- within these scenarios they understand marketplace conditions and drivers, have structured around key segments and formulated strategies (which can be changed as circumstances change), supported by detailed action, contingency and resource plans (marketing planning)

- within the existing and developing customer base they understand their portfolios and where their profits come from. Furthermore, they understand how to keep their most valued customers and how to develop other customers into more valuable customers (CRM).

To undertake CRM without this structure is to miss the point. If a business has ten customers and seven of them are in a fast-declining segment of the market, which may vanish in five years' time, it would be foolish to concentrate on these, regardless of how profitable they are today. A detailed assessment of lifetime values should clearly indicate the impending crisis but no CRM approach will identify how to change. Only marketing planning, in the context of scenario planning in difficult times, can offer that.

\section{References}

1 Reichheld, F. F. (1996) 'The loyalty effect: the hidden force behind growth, profits and lasting value', Harvard Business School Press, Boston, p. 322.

2 Stifler, J. (2001) 'What others have learned while implementing CRM', CRMguru.com.

3 Gartner press release, 10th September, 2001. http://www.gartner.com/5_about/press_releases/ 2001/pr20010912b.html.

4 Fletcher, K. and Wright, W. (1997) 'Strategic and organisational determinates of information system sophistication: An analysis of the uptake of database marketing in the financial services industry', European Journal of Information Systems, Vol. 6, pp. 141-154.

5 Galliers, R. (1991) 'Strategic information systems planning: Myths, reality and guidelines for successful implementation', European Journal of Information Systems, Vol. 1, No. 1, pp. 55-64.

6 Levitt, T. (1960) 'Marketing myopia', Harvard Business Review, July/August, pp. 45-56.

7 Peppers, D. and Rogers, M. (1993) 'The one to one future', Currency Doubleday.

8 Hart, S. et al., (1999) 'Are loyalty schemes a manifestation of relationship marketing?', Journal of Marketing Management, Vol. 15, No. 6, pp. 541-562.

9 O'Brien, L. and Jones, C. (1995) 'Do rewards really create loyalty', Harvard Business Review, Vol. 73, May/June, pp. 75-82.

10 Goldsmith, N. (1991) 'Linking IT planning to business strategy’, Long Range Planning, Vol. 24, No. 6, pp. 67-77.

11 Ward, J. (1987) 'Integrating information systems into business strategies, Long Range Planning, Vol. 20, No. 3, pp. 19-29.

12 Wiseman, C. and Macmillan, I. C. (1984) 'Creating competitive weapons from information systems', Journal of Business Strategy, Vol. 5, No. 2, pp. 42-49.

13 Fletcher, K. and Wright, G. (1995)

'Organisational, strategic and technical barriers to successful implementation of database marketing', International Journal of Information Management, Vol. 15, No. 2, pp. 115-126.

14 Desai, C., Wright, G. and Fletcher, K. ((1998) 'Barriers to successful implementation of database marketing: A cross-industry study', International Journal of Information Management, Vol. 18, No. 4, pp. 265-276.

15 Seybold, P. and Marshak, R. (1998) 'Customers.com Handbook: An executive guide and technology roadmap for your customer.com initiatives', www. customers.com, 85 Devonshire Street, Boston MA 02109 USA.

16 Peppers, D., Rogers, M. and Dorf, B. (1999) 'The one to one fieldbook: The complete toolkit for implementing a one-to-one program', Currency, Doubleday.

17 Catalyst (2001) 'The catalyst CRM methodology: An overview', European Centre for Customer Strategies (ECCS), www.eccs.uk.com.

18 Curry, J. et al. (1998) 'Customer marketing: How 
to improve the profitability of your customer base', Kogan Page.

19 Gartner (2001) op. cit.

20 Stifler (2001) op. cit.

21 McDonald, M. (1999) 'Marketing plans: How to prepare them: How to measure them', Heinemann, Oxford.

22 Chan, Y. E., Huff, S. L. and Copland, D. G. (1997) 'Business strategic orientation, information systems strategic orientation, and strategic alignment', Information Systems Research, (ISR) Vol. 8, No. 2, p. 125.
23 MacDonald, H. (1991) 'Business strategy development, alignment and redesign', in Scott Morton, M. S. (ed.) 'The corporation of the 1990s', Oxford University Press, NY.

24 Chalder, M., Gamble, P. and Stone, M. (2000) 'Managing good and bad customers in practice', Journal of Database Marketing, Vol. 7, No. 4, pp. 356-380.

25 Nolan, R. (1979) 'Managing the crises in data processing', Harvard Business Review, March/April, pp. 115-126. 